\title{
Acute necrotic myelopathy associated with perivenous encephalomyelitis
}

\author{
THE LATE H. L. HOFFMAN AND R. M. NORMAN \\ From the Royal United Hospital, Bath, and the Burden Neuropathological Laboratory, Frenchay Hospital, \\ Bristol
}

In this paper we record a case in which occurred the uncommon association of necrotic softening in the lower half of the spinal cord and acute disseminated encephalomyelitis of perivenous type. The myelomalacia, in its topographical features, corresponded closely to that reported by Kahle and Schaltenbrand (1955) in their cases of 'myelitis necroticans diffusa' and we shall use the descriptive term 'acute necrotic myelopathy' as in an earlier paper (Hoffman, 1955). The perivenous encephalomyelitis showed the long sleeve-like areas of demyelination around small veins commonly seen in post-vaccinal or postexanthematous encephalomyelitis. In this condition necrosis of the cord hardly ever occurs and our main purpose is to stress the rarity of the histologically proven combination of lesions. In addition we shall discuss the role of oedema in the pathogenesis of myelomalacia of this type.

\section{CASE REPORT}

A.B., aged 57, a carpenter, gave a history of chronic cough with sputum of many years' duration. He was demobilized from the Army in 1945, being graded category B, probably because of an anxiety state. On 14 February 1959 he developed coryza which lasted for four days, leaving him with a cough and purulent sputum. On 19 February he noticed that he was dragging his right leg, and on 23 February that the left side of his face felt puffy. On trying to get out of bed on the following day he found that he could not stand on his right leg, which gave way completely. His right arm felt weak and he experienced paraesthesiae from the middle of the right forearm to the fingers. He noticed also that his speech was less distinct than usual. There had been no headache, except with the coryza, and no visual disturbance.

Later on 24 February he was admitted to the Royal United Hospital, Bath. His temperature was $98.4^{\circ} \mathrm{F}$. $\left(37^{\circ} \mathrm{C}\right.$.), the pulse rate 72 per minute, and respirations 20 per minute. He had not passed urine since the previous night and was suffering from retention. He was catheterized and $40 \mathrm{oz}$. $(1 \cdot 141$.) of urine was obtained. His tongue was slightly furred but moist; in the abdomen there was no tenderness after catheterization and no abnormal viscera or masses were felt. Crepitations were heard at both lung bases. The cardiac apex beat was felt in the fifth interspace, outside the mid-clavicular line, the heares sounds were normal and no murmurs were heard. The blood pressure was $150 / 100 \mathrm{~mm}$. $\mathrm{Hg}$.

On examination of the central nervous system it was $\overrightarrow{\vec{\omega}}$ noted that the patient's speech was slurred. Apart fromp impaired perception of light touch and pin prick on the right side of the face, no other abnormalities were found in the cranial nerve functions. The optic discs were normali There was some weakness of the right arm and leg with increased muscle tone, the tendon reflexes were increased in these limbs, and there was clonus at the right ankle $\vec{\sigma}$ Both plantar responses were flexor. The abdominal reo flexes were absent. Pin prick and light touch were less well? perceived on the left side of the body but sense of position was normal.

Examination of the blood showed haemoglobin 9 $(13 \cdot 3 \mathrm{~g} . \%)$, leucocytes 9,000 per c.mm. (73\% polymorp 50 - $\overrightarrow{0}$ nuclear cells, $20 \%$ lymphocytes); the Arneth counp showed a moderate shift to the left. The sedimentation rate was $27 \mathrm{~mm}$. in one hour (Westergren). The urineo initially contained no abnormality. On 25 February as lumbar puncture was performed revealing no evidence of spinal block. The cerebrospinal fluid was clear an\& colourless containing protein, $75 \mathrm{mg} . \%$, with no increase in globulin. There were 3 lymphocytes per c.mm. The sugar was $70 \mathrm{mg} . \%$ and the chlorides $690 \mathrm{mg} . \%$. The Lange curve showed no abnormality and the Wasser mann reaction of the fluid was negative.

On 25 February the left leg became weak and on the following day there was a flaccid paraparesis with a sen sory level at the fifth dorsal segment; in the arms there was slight incoordination in the finger-nose test. Moist sounds now appeared in the chest and as there was a poos cough reflex with difficulty in swallowing, a tracheostomy was performed. Later in the day the patient's breathing became difficult and positive pressure assisted respiration with a Radcliffe respirator was started; on 27 February? however, he was breathing spontaneously. By 1 March he had improved still further and on 7 March the endo tracheal tube was removed. During that night, however his breathing again became difficult and the chest was fulfs of moist sounds. A bronchoscopy and aspiration was car $\sim$ ried out, the endotracheal tube being replaced. OrN 9 March collapse of the left lung necessitated further bronchoscopy which was repeated on 10 March. On this day he was first seen by one of us (H.L.H.) when it waso 
considered that the cord had become extensively destroyed. The sensory level had risen to the second or third dorsal segment and the physical signs remained unchanged until his sudden death on 16 March, the 26th day of his neurological illness.

On admission the patient was given prednisone, $15 \mathrm{mg}$. six hourly, the dose being gradually reduced to $2.5 \mathrm{mg}$. six hourly on 3 March, and the drug was withdrawn on 11 March. In addition, chloramphenicol, $1 \mathrm{~g}$., was given on 26 March and $0.25 \mathrm{~g}$. six hourly thereafter until 5 March. A further short course of double these quantities was given between 8 and 12 March, the period during which bronchoscopy was carried out.

\section{NEUROPATHOLOGICAL EXAMINATION}

Examination of the nervous system will alone be described as it revealed the chief points of interest.

MACROSCOPIC The brain weighed $1,447 \mathrm{~g}$. after fixation. The external appearance was unremarkable and the ventricles were of normal size. On dissection multiple small greyish areas suggesting demyelination were seen in the white matter of the right occipital lobe and a larger focus of similar appearance was found in the left cerebellar hemisphere.

The spinal cord (Fig. 1) appeared normal down to the level of T2 where there was a small crescentic area of discoloration on the dorsal aspect. Below this level it became shrunken and the surface vessels were engorged in the remainder of its length. There were marked irregularities of contour from the seventh to tenth thoracic segments; in this region the cord had the consistency of ripe Camembert cheese. On section areas of softening were found in the posterior columns.

MICROSCOPIC Representative celloidin and frozen sections were prepared from the cerebral cortex, basal ganglia, cerebellum, and brain-stem. Each spinal cord segment from the second cervical to the third sacral inclusive was embedded in celloidin, parts of some segments having been reserved for frozen sections. Standard methods of staining for nerve cells, axis cylinders, myelin, fibrous neuroglia, and lipid were employed.

Spinal cord The only abnormality seen in the upper cervical segments was an increased cellularity of the columns of Goll due to microglial proliferation. The sixth cervical segment showed a small focus of perivenous demyelination at the margin of one anterior horn. This area was densely infiltrated with microglial cells. At the level of $\mathrm{C7}$ there was extensive demyelination along the course of veins in the anterolateral columns of one side and to a limited extent in the anterior column of the other (Fig. 2). The anterior horn on the more affected side was also demyelinated but the neurones were intact (Fig. 8). Myelinated fibres had disappeared from the perivenous zones and the periphery was formed by a fringe of swollen and palely staining fibres. Axis cylinders, on the other hand, were numerous, the majority showing intense swelling. Large numbers of microglial cells were present and many fat granule cells could be seen. Fibrous neuroglia was increased in the affected anterior horn but not in the demyelinated patches in the white matter.

Sections taken from the next two segments (C8 and T1) showed no abnormality except for the cellularity of the columns of Goll already noted at the higher levels. In T2 there was a large patch of demyelination of irregular outline involving the posterior and lateral columns and the posterior horn of one side (Fig. 3). This area had similar histological features to the lesions at $\mathrm{C7}$ and appeared to be formed by confluence of perivenous zones of demyelination. The posterior column contained an area of early fibrous gliosis but elsewhere there was no astrocytic reaction.

T3 exhibited changes unlike any yet encountered. In the celloidin sections a small circular area resembling an early infarct was found at the base of one posterior column. Within a peripheral ring of microglial cells the myelin sheathes had lost their haematoxyphil property though the faint greyish outlines of swollen fibres were still visible. Some of the latter stained intensely in Nissl preparations and appeared to be necrotic. In frozen sections taken from a lower part of the same segment this circular area had expanded to a diameter of about $3 \mathrm{~mm}$. and had involved the base of both posterior columns. The marginal microglial cells were loaded with scarletstaining lipid but the central, necrotic regions contained only sparse lipid droplets. The tissue in this region presented a fragmented appearance and readily fell out of sections. It stained less intensely with Scharlach $\mathbf{R}$ than normal myelin but still showed considerable birefringence. The same type of lesion, though now mainly confined to the base of one posterior column, was still present in the fourth thoracic segment and in T5 the picture was complicated by widespread patches of perivenous demyelination. A large area in the lateral columns of one side showed a spongy or areolar type of demyelination (Fig. 4). In T6 no normal myelinated fibres were seen, the whole section staining a grey colour and showing intense swelling of the axons. Here and there dense accumulations of fat granule cells were present round the vessels and infiltrated the tissues diffusely. The meninges over the anterior columns had been ruptured and part of the loosened tissue of the cord had disappeared. No distinction between grey and white matter could be discerned. $T 7,8$, and 9 were shrunken and showed a more homogenous 


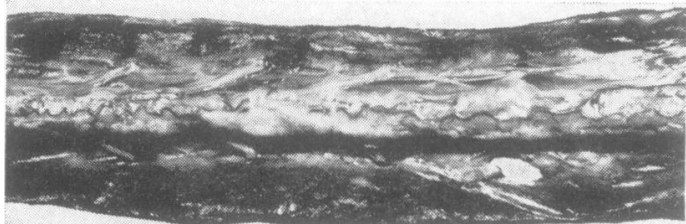

FIG. 1. Mid-dorsal cord showing necrosis. The contours are irregular and the surface vessels engorged.

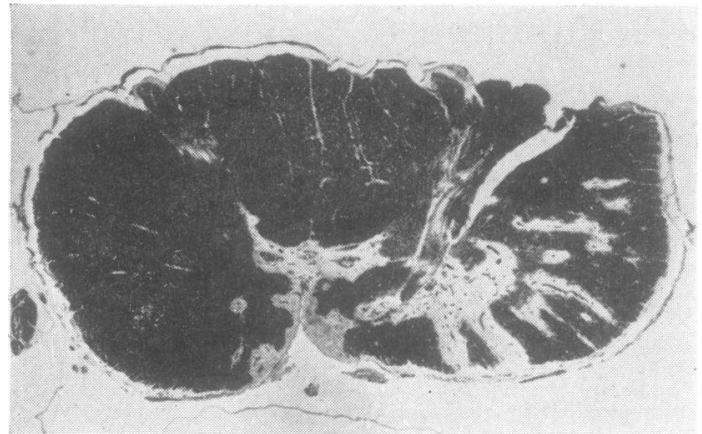

FIG. 2. C7. Perivenous demyelination. Heidenhain $\times 6$.

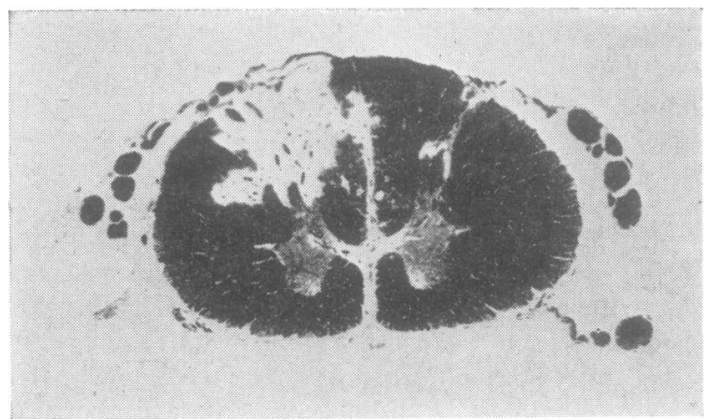

FIG. 3. T2. Confluent patches of perivenous demyelination. Heidenhain $\times$ 5.5.

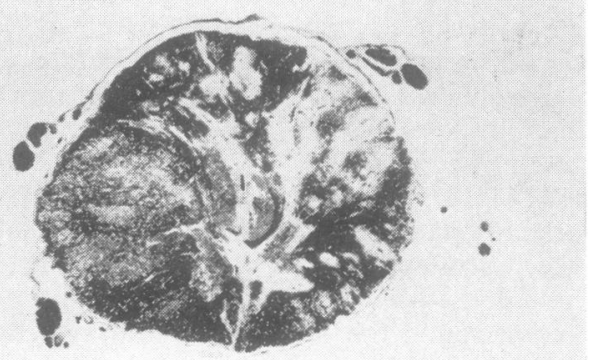

FIG. 4. T5. An area of spongy, diffusely demyelinated tissue is seen in the left lateral region. Elsewhere there are typical perivenous lesions. Heidenhain $\times 5.5$. texture, with absence of normally myelinated fibresD The nuclei generally stained poorly and there was no microglial proliferation. In the grey matter most of the nerve cells had disappeared, only a few shadow cells remaining. Hyalinization of the walls of the intraspinal vessels was a prominent feature and ther was some lymphocytic cuffing. T10 was remarkable . for the additional feature of numerous fat granule cells in the grey matter. Small recent haemorrhages were also present. At T11 (Fig. 5) and T12 patches of fat granule cells were seen in the posterior and laterat columns, the vessels being conspicuously dilated if the former situation. As at higher levels, the whole. cord showed swollen, poorly staining myelin sheathso

The picture remained much the same in the firsf three lumbar segments though it became apparenfe that increasing damage was occurring in the posterio $\vec{D}$ columns. At the level of L4 there was a marked im provement in the myelination of the anterior and lateral tracts, though small patches of perivenous demyelination were present. The anterior horns were well myelinated and the nerve cells were not reduced in number, though most showed swelling and chro matolysis. The posterior columns, however, except at their dorsal margins, were demyelinated and a $\vec{\Phi}$ their bases exhibited the same sort of circular are? of necrosis as was seen at T3 (Fig. 6). This area was partially walled in by a zone of fat granule ce्llis Longitudinal sections of the lumbar cord showe 9 considerable loss of axis cylinders in this necrotie area, many of the survivors being greatly swolfinos tortuous, fragmented and ending in ball-shaped swellings, loops, or tangles. This area of severe damage gradually increased in extent in lower segs ments reaching its maximal stage in the sacra $\bar{\phi}$ region (Fig. 7).

Nerve roots, meninges, and extraspinal vessels $A \AA$ the levels of severe demyelination the posterior root $\vec{E}$ near the zone of entrance often showed massive los of myelinated fibres and large collections of fas granule cells (Fig. 9). In the same regions the lepto meninges were heavily loaded with fat granule cells. Lymphocytic cuffing of veins was occasionally present but was not a conspicuous feature. No plasmas cells were seen. The arteries appeared normal except. that in one of the sections stained for lipid the anterior spinal artery showed endothelial thicken ing with heavy fat deposits.

Cerebral hemispheres The white matter of the right occipital lobe contained numerous perivenous foci of demyelination some of which had formed con fluent patches (Fig. 10). The vessels were denselø ringed with fat granule cells while the adjacent areas of demyelination contained a variable number of diffusely distributed cells of similar type. These foc showed a well-marked fibrillary gliosis (Fig. 11), and 


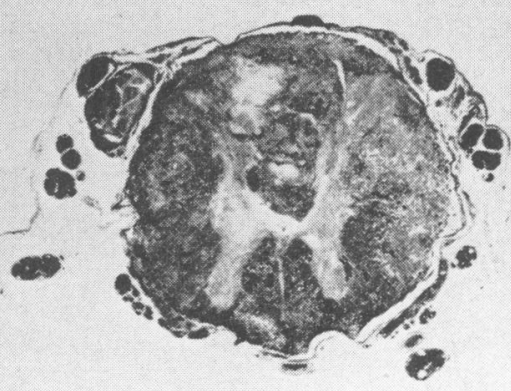

FIG. 5

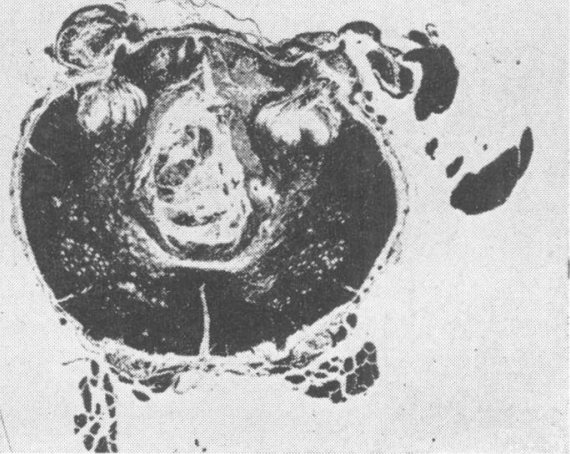

FIG. 7

FIG. 5. T11. Generalized pallor of grey and white matter. The posterior columns show patches of complete loss of myelin, and there is partial demyelination of a posterior nerve root. Heidenhain $\times 5.3$.

FIG. 6. L4. Necrosis at the base of the posterior columns. Patches of perivenous demyelination are seen in the left lateral column. Heidenhain $\times 5.6$.

FIG. 7. S1. Softening and liquefaction of the greater part of the posterior columns. Heidenhain $\times 5.4$.

FIG. 8. C7. The demyelinated areas in the grey and white matter are inflitrated with microglial cells. The anterior horn cells are preserved. Carbol azure $\times 30$.

the axis cylinders were invariably destroyed. Round the tip of the occipital horn larger confluent patches of demyelination were seen. The cellular infiltration of these foci was denser and there was less fibrous neuroglia, though numerous swollen-bodied astrocytes were present. A few highly cellular and demyelinated perivenous foci were also found elsewhere in the white matter of the brain, namely, in the isthmus of the temporal lobe, close to the angle of the lateral ventricle, in the internal capsule, and in the centrum ovale. A section from the white core

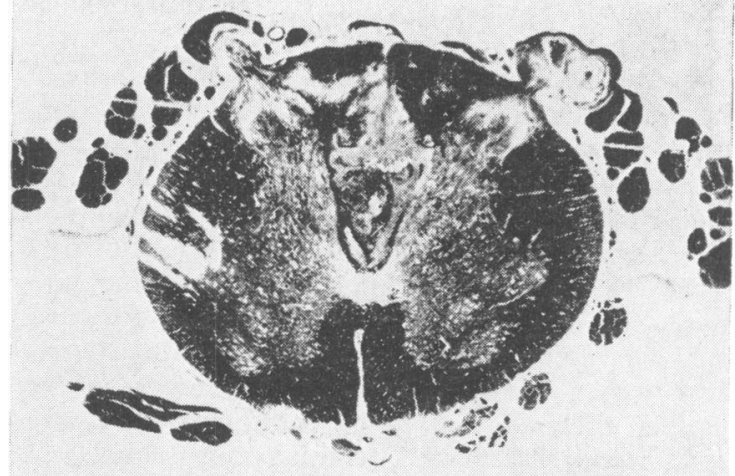

FIG. 6

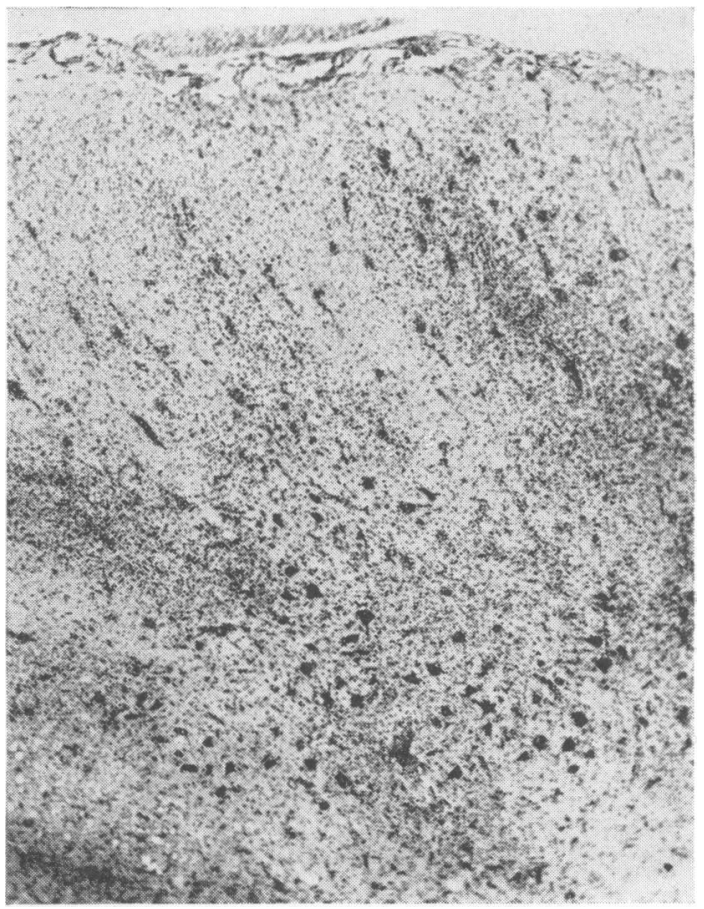

FIG. 8

of the left inferior frontal gyrus showed very clearly that the demyelination followed a vessel for a long distance in the form of a sleeve.

Cerebral cortex The numerous areas examined showed no abnormality as regards nerve cell population or myelination. The basal ganglia were normal in all respects.

Optic pathways No abnormal changes were seen in the optic chiasma or in the posterior portions of optic nerves that were available for examination. In the left optic tract, near its junction with the chiasma, 
there were three small foci of perivascular demyelination (Fig. 12).

Brain-stem No lesions were seen in sections of the mid brain and medulla. The pons was also unremarkable except for a perivenous focus in each middle peduncle.

Cerebellum A large area of partial demyelination of peculiar type occupied much of the posterior part of the left lateral lobe of the cerebellum (Fig. 13). Medially it separated into two parts lying above and below the dentate nucleus. In myelin preparations there was a considerable diffuse reduction in the number of fibres, and the borders of the area were crenated and ill defined. There was poor staining and

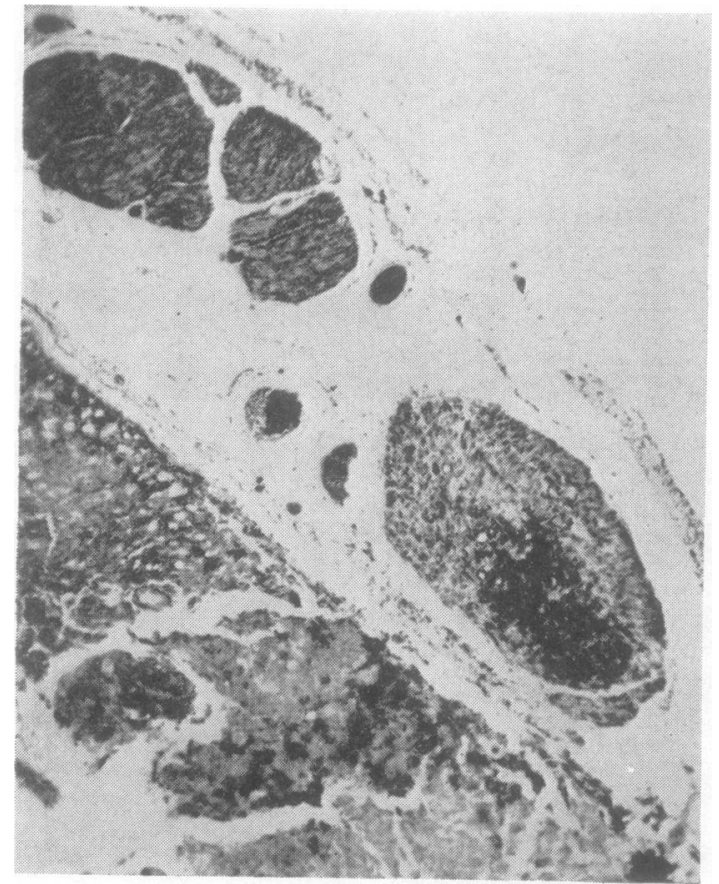

FIG. 9. T7. A posterior nerve root shows massive aggregation of fat granule cells. Scharlach $R$ and haematoxylin $\times 35$.

varicosities in many of the remaining fibres, particularly at the periphery of the area. Axis cylinders were also reduced in numbers. In Nissl staining the ground substance was pale and the area relatively acellular, the remaining nuclei staining feebly. There was no fibrous gliosis, swelling of astrocytes, or visible lipid. The marginal zone showed a slightly increased cellularity and vacuolated, swollen microglial cells were present, but these did not contain lipid. No swollen oligodendrocytes were recognized.

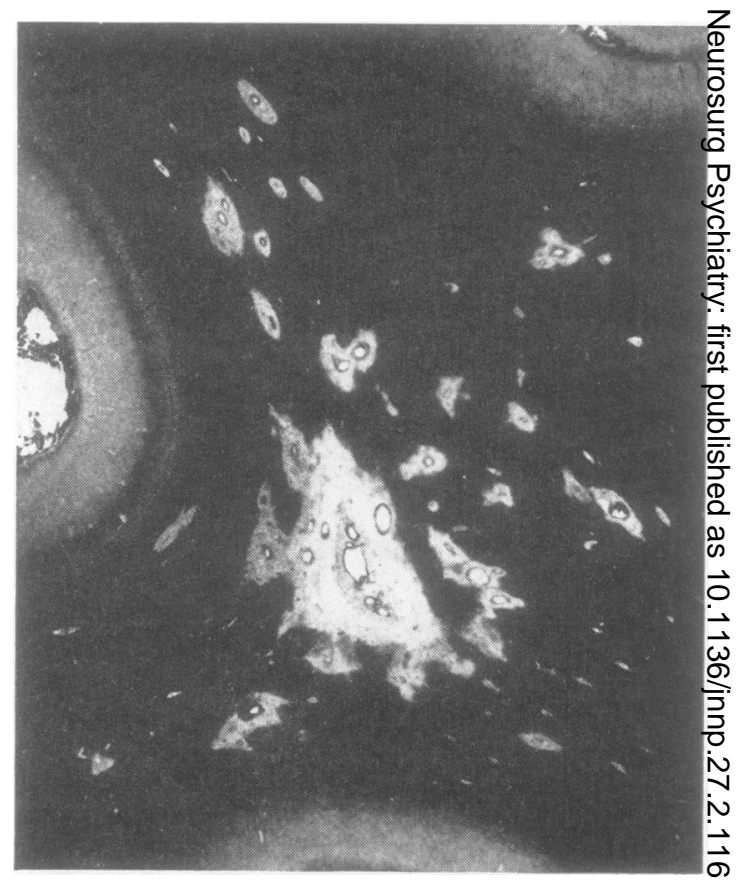

FIG. 10. Right occipital lobe. There are numerous peri을 vascular foci of demyelination, some of which are confluest $\rightarrow$ Heidenhain $\times 7$.

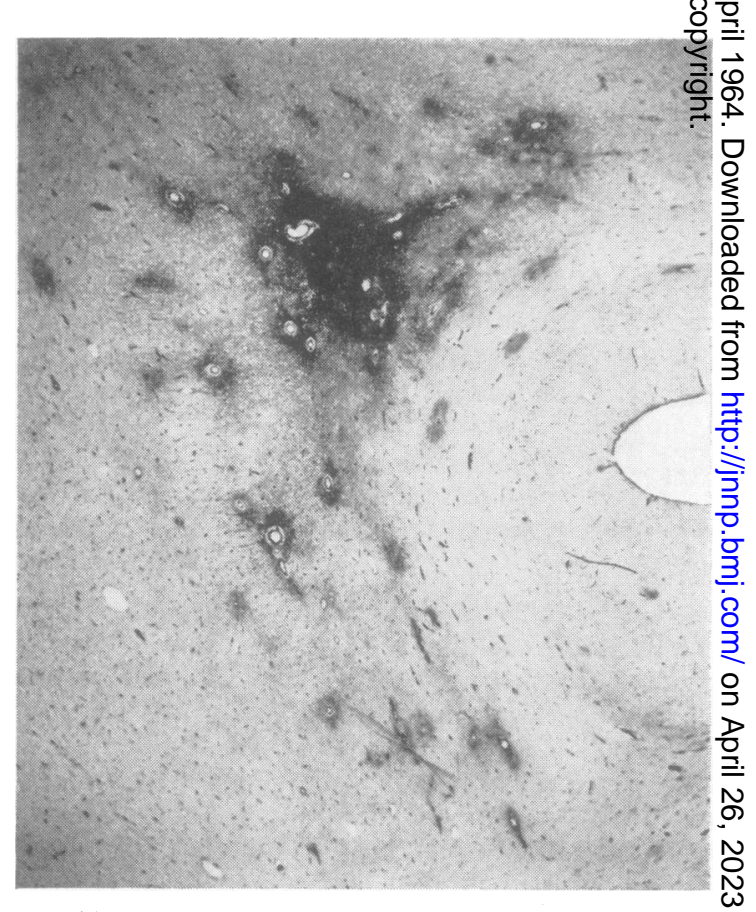

FIG. 11. Same area as in Fig. 10 showing fibrous gliosis Holzer $\times 7$. 


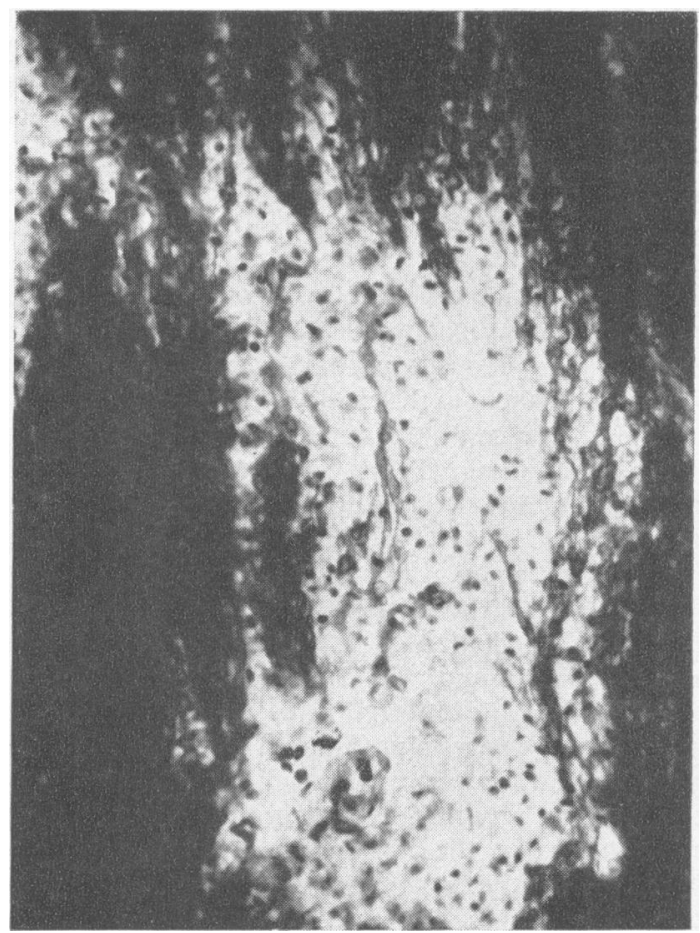

FIG. 12. Left optic tract near the chiasma, with a patch of demyelination. Kultschitsky.Pal $\times 240$.

The nerve cells of the dentate nucleus showed widespread pathological changes. There were many shadow cells, only recognizable as neurones from their lipochrome content. Other nerve cells showed chromatolysis with feeble nuclear staining. The cell band was abnormally cellular in places owing to the prominent staining of the endothelial nuclei of congested capillaries and the presence of numerous microglial cells which sometimes formed figures of neuronophagia around degenerate nerve cells. Some of the microglia in these areas contained scarletstaining lipid granules but in general there was very little intra- or extracellular fat in the tissues. In contrast to the demyelinated area in the central white matter there was considerable fibrous gliosis in the hilum of the dentate nucleus. The nyelinated fibres of the grey matter of the nucleus varied considerably in their state of preservation. Those in the areas showing severe neuronal changes were reduced in numbers and showed marked beading. The cerebellar cortex appeared intact.

\section{DISCUSSION}

The striking features of this case were the appearance of necrosis in certain segments of the spinal cord and the presence elsewhere of perivenous encephalo-

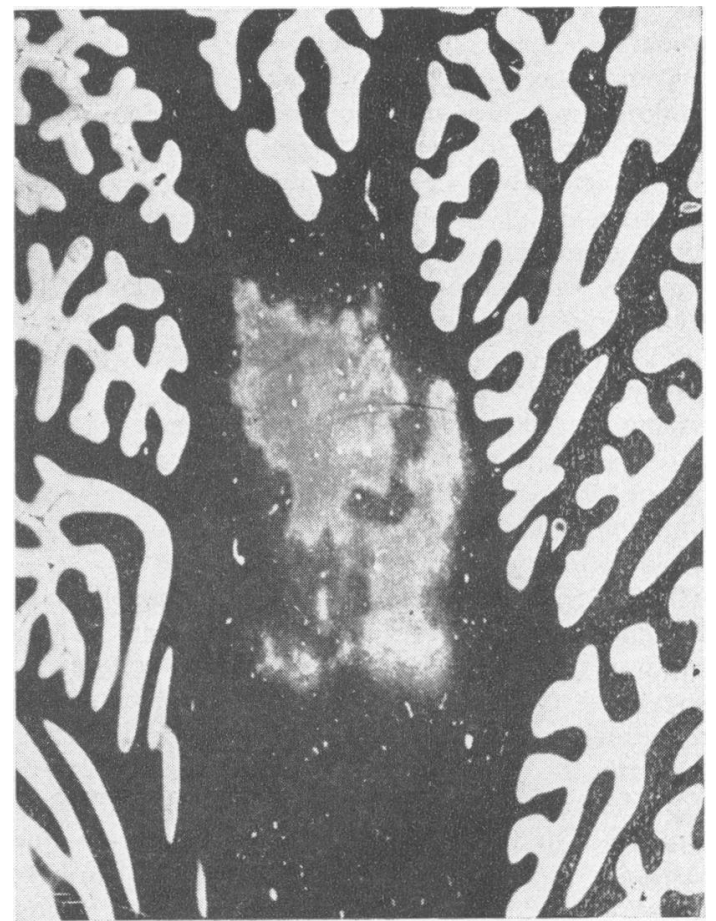

FIG. 13. Cerebellum. Oedematous necrosis of the white matter. Heidenhain $\times 3.7$.

myelitis. In our experience we have not seen a similar association and very few other examples have been reported. In examining the literature we considered the classic descriptions of post-infective encephalomyelitis, post-vaccinal encephalomyelitis, and that following anti-rabies treatment, also reports of acute necrotic myelopathy and the well-known accounts of neuromyelitis optica, in which cord necrosis may sometimes occur.

The case which histologically most closely resembled our own was that described by Troup and Hurst (1930). Their patient was a man aged 65 who developed the first symptoms of paraplegia 15 days after the onset of smallpox and 11 days after the appearance of the rash. He died on the 26th day of his neurological illness. The lesions, situated in the spinal cord, brain-stem, and cerebellum, consisted of areas showing perivascular demyelination and cellular infiltration. The cells were made up of a small percentage of lymphocytes and an occasional plasma cell, the majority being granular corpuscles heavily loaded with the lipid products of myelin degeneration. The changes were indistinguishable from those of acute perivascular myelinoclasis described later by Marsden and Hurst (1932), except that the spinal cord, from the middle lumbar region downwards, 
was reduced to a very soft greyish pink mass which, at necropsy, could only be removed as pulp.

We have been unable to find any other example in the literature where post-exanthematous encephalomyelitis was associated with acute necrosis of the cord. A case was described by De Busscher and Radermecker (1949) in which a man aged 20 died from ascending myelitis in five days, having received smallpox vaccination and T.A.B. prophylaxis four weeks previously. Histologically the cord showed small foci of perivascular demyelination which were sometimes confluent. In addition there was perivascular cellular infiltration. In the cervical region lesions along the capillaries of the corona radiata of the cord were said to converge on 'a greater necrotic zone', but it is not certain whether there was in fact actual softening.

In the paralytic accidents of rabies prophylaxis, perivenous demyelinating encephalomyelitis is a common finding. Babes and Mironesco (1908) reported the case of a 40-year-old woman who was treated six days after the bite of a rabid dog. Fourteen days later treatment was stopped because of paralysis of the legs and the patient died on the day following admission to hospital. Oedema of the brain and meninges was found with extensive destruction of the cord in the lower dorsal and lumbar regions. Here the white and grey matter were indistinguishable and the cord had been reduced to 'une pulpe griserose'. In addition to destruction and oedema of nerve fibres the authors noted a perivascular cellular reaction. There is no doubt that this was a case of cord necrosis, but it is not entirely clear from the description if the changes elsewhere were typical of perivenous encephalomyelitis. It is of interest, however, that Greenfield (1930) mentioned this case and thought that the findings closely resembled those of acute disseminated myelitis.

Among cases of perivenous encephalomyelitis which follow an upper respiratory tract infection or 'influenza', such as those described by Greenfield (1930), it is equally difficult to discover evidence of cord necrosis. However, a case somewhat similar to our own was reported by Dorothy Russell (1955) in a discussion regarding the nosological unity of acute haemorrhagic leucoencephalitis and acute disseminated encephalomyelitis. This patient was a woman aged 39 who developed headache and vomiting for one hour five days after an influenza-type cold. Four days later there was an episode of retention of urine; in a further six days she was admitted to hospital having developed weakness and numbness of the legs during the previous two days, and also constant dribbling incontinence of urine. Respiratory paralysis followed and she died five days later, death having occurred 12 days after the onset of neurological symptoms and nine days after the first evidence of cord involvement. Pathological examination showed perivascular demyelinating lesions chiefly in the brain-stem and cord, although there were a few irf the cerebral hemispheres. The cord was described astron uniformly soft and swollen. Scattered haemorrhageso were seen and the demyelinated areas were becoming confluent.

In cases of acute necrotic myelopathy or myelitis: necroticans described in the literature the association of frank perivenous encephalomyelitis such as thato which was present in the case of A.B. was not evident.음 Among references to this subject are the following:- क Bassoe and Hassin (1921), Schmitt (1921), Moersch $\mathbb{Q}$ and Kernohan (1934), Juba (1938), Schunk ando Kernohan (1939), Greenfield and Turner (1939), Jaffe and Freeman (1943), Gagel and Reiner (1943), Hurst (1944), André (1946), Radermecker (1946), Géreb (1950), Zeitlhofer (1950), Klaue (1951), Kahle and Schaltenbrand (1955), and Trevor Hughes. (1961). One of us reported three cases of acute cordó necrosis some years ago (Hoffman, 1955), and therev was no sign of perivenous demyelination in any of thẹ cords. There are, however, several reports of demy $-\vec{z}$ elinated areas of the brain or brain-stem, resembling $\bar{\sigma}$ those of multiple sclerosis, being found in cases of acute cord necrosis. Conversely, in established cases of multiple sclerosis cord necrosis has occurred as terminal event.

One might reasonably expect to find cases simitiric to our own in the literature concerning neuromyelitis? optica, but so far as we can determine they are un common. (Cases described by Walsh (1935) and Stansbury (1949) might possibly be cited as examples.) This ill-defined syndrome would seem toin depend for identification on the topography of itso lesions, situated in the cord and optic pathways $\cong$ rather than on definite clinical or pathological con-0 siderations. Thus a variety of histological changes have been described, which include localized plaques of demyelination resembling those of multiple. sclerosis. Much larger diffuse lesions are often found which, when seen in the brain, resemble those of Schilder's disease while in the cord considerable areas? of necrotic softening may occur. Some authors con:sider that the earliest lesions of neuromyelitis optica consist of foci of perivascular demyelination? 'Perivascular' foci, however, are common in multiple? sclerosis, especially of the acute type, and are not to be equated with the long, sleeve-like areas of demye lination of uniform calibre which characterize acutê disseminated encephalomyelitis, a point clearly made by Lumsden (1957). The presence of lesions in the cord and optic pathways might well place our case int the category of neuromyelitis optica, but the simulo taneous occurrence of frank perivenous demyelinaco 
tion and cord nesrosis would appear to be unusual in this condition.

PATHOGENESIS OF ACUTE NECROTIC MYELOPATHY Most of the reported cases of necrotic myelopathy of varying aetiology show a striking uniformity in the distribution of the softenings. These are found mainly in the central parts of the cord, particularly in the base of the posterior columns, and they often assume a spindle shape in longitudinal sections. It does not seem likely that this almost stereotyped localization is solely due to an increased intensity in the demyelinating process in these areas. Various authors have mentioned swelling of the cord in their descriptions of necrotic myelopathy. In the paper on this subject by one of us (Hoffman, 1955), Professor Hewer drew attention to this finding in his pathological report on case 2 . He considered that oedema might well be responsible for the necrosis, owing to the pressure produced within the cord. Oppenheimer (1962) has discussed a case where multiple sclerosis was associated with cord necrosis. He suggested that the extensive demyelination may have led to swelling of tissue closely invested by a tube of relatively inelastic pia mater. This would tend to obstruct the circulation and lead to softening. In the case of A.B. the position of the most cephalic area of softening occurred at T3-T4 level, segments known to have a relatively poor boundary zone of arterial supply and to be at risk in conditions of circulatory insufficiency (Schneider and Crosby, 1959). A similar explanation has been given by Keener (1955) to account for necrosis found in association with intramedullary spinal abscess. He suggested that the swelling produced by the abscess would compress capillaries and veins with resulting ischaemic lesions. It is of interest to note that a small intramedullary abscess was found by van Gehuchten (1927) in a case of necrotic myelopathy, and in case 3 of the paper mentioned above (Hoffman, 1955). Keener also quotes the findings of Holmes (1915), who described cavities above and below the site of local cord injuries. These contained necrotic material under increased pressure.

In our case there was no evidence of swelling of the cord; it was, in fact, shrunken in the affected portion. This shrinkage is well recognized in patients who survive the initial illness for any length of time, and swelling has been described in cases of shorter duration. It is probable that oedema had been present at some earlier stage, and the suggestion receives support from the presence of a lesion, attributable to oedema, elsewhere in the central nervous system. This was the large patch of demyelination in the central white matter of the cerebellum. In this site the factor of constriction by pia mater was lacking and softening of the tissues had not taken place. We are in- debted to Dr. van Bogaert, who kindly examined the sections from the cerebellum, and confirmed that this unusual lesion was one of 'oedematous necrosis'. It is possible that this oedema does not result merely from an intensification of the demyelinating process. It may represent a non-specific sensitivity reaction such as that which is presumed to occur in the neurological complications of serum therapy. In the present case and in others where, in addition to the cord necrosis, there are lesions of a demyelinating disease, it may well be that the antigen is a product of myelin breakdown.

TREATMENT Corticosteroids and corticotrophin (A.C.T.H.) are known to produce good results in cases of retrobulbar neuritis, especially where the presence of oedema in the optic nerve is suggested by swelling of the disc. Their use would, therefore, appear to be indicated in the stage of oedema before the cord has actually become necrotic. Unfortunately in cases of 'idiopathic' necrotic myelopathy the diagnosis can rarely be established early enough and much time is necessarily spent on investigations to exclude cord compression, tumour, or abscess. It is suggested, however, that if signs of an acute cord lesion develop in a case of multiple sclerosis or following retrobulbar neuritis, as in so-called 'neuromyelitis optica', corticotrophin should be given without delay in the large doses recommended by Miller, Newell, and Ridley (1961) if no contraindications to its use are present. Only by this means can one hope to halt the process of swelling which will otherwise destroy the cord.

\section{SUMMARY}

The case recorded showed the unusual conjunction of acute necrotic myelopathy and perivenous encephalomyelitis. Apart from this, it appeared to illustrate a pathogenetic mechanism which may well operate in other conditions of diverse aetiology associated with softening of the cord, namely, compression of vessels following initial oedematous swelling of the tissues. Obstruction of circulation by this means would in turn lead to myelomalacia. In view of the suspected oedema in these cases, treatment with large doses of corticotrophin is suggested, provided that a reasonably firm diagnosis can be made at an early stage.

The authors have pleasure in recording their thanks to Dr. L. C. Hill for referring this patient who was under his care.

\section{REFERENCES}

André, M. J. (1946). Arch. belges Méd. soc., 4, 412.

Babes, V., and Mironesco, T. (1908). C.R. Soc. Biol. (Paris), 64, 964. 
Bassoe, P., and Hassin, G. B. (1921). Arch. Neurol. Psychiat. (Chic.), 6, 32.

De Busscher, J., and Radermecker, J. (1949). Acta neurol. belg., 49. 374.

Gagel, O., and Reiner, E. (1943). Z. ges. Neurol. Psychiat., 175, 333.

Géreb, T. (1950). Mschr. Psychiat. Neurol., 120, 237.

Greenfield, J. G. (1930). J. Path. Bact., 33, 453.

- and Turner, J. W. A. (1939). Brain, 62, 227.

Hoffman, H. L. (1955). Ibid., 78, 377.

Holmes, G. (1915). Brit. med. J., 2, 769.

Hughes, J. T. (1961). M.D. Thesis, Victoria University of Manchester.

Hurst, E. W. (1944). Brain, 67, 103.

Jaffe, D., and Freeman, W. (1943). Arch. Neurol. Psychiat. (Chic.), $49,683$.

Juba, A. (1938). Dtsch. Z. Nervenheilk., 148, 17.

Kahle, W., and Schaltenbrand, G. (1955). Ibid., 173, 234.

Keener, E. B. (1955), Brain, 78, 394.

Klaue, R. (1951). Dtsch. Z. Nervenheilk., $166,137$.
Lumsden, C. E. (1957). H1le Congrès International de Neuropatho- $-\mathbb{D}$ logie, Brussels, 1957, p. 26.

Marsden, J. P., and Hurst, E. W. (1932). Brain, 55, 181.

Miller, H., Newell, D. J., and Ridley, A. (1961). Lancet, 2, 1120.

Moersch, F. P., and Kernohan, J. W. (1934). Arch. Neurol. Psychiat (Chic.), 31, 504

Oppenheimer, D. R. (1962). D.M. Thesis, Oxford University.

Radermecker, J. (1946). J. belge Neurol. Psychiat., 44-46, 781.

Russell, D. S. (1955). Brain, 78, 369.

Schmitt, W. (1921). Dtsch. Z. Nervenheilk., 72, 78.

Schneider, R. C., and Crosby, E. C. (1959). Neurology (Minneap.) 9, 643 .

Schunk, P., and Kernohan, J. W. (1939). Rocky Mtn med. J., 36, 789.

Stansbury, F. C. (1949). Arch. Ophthal., 42, 292 and 465.

Troup, A. G., and Hurst, E. W. (1930). Lancet, 1, 566.

van Gehuchten, P., (1927). Rev. neurol., 34, (2), 177.

Walsh, F. B. (1935). Bull. Johns Hopk. Hosp., 56, 183.

Zeitlhofer, J. (1950). Wien. Z. Nervenheilk., 3, 344. 